\title{
Teaching Design of Integrated Course of Reading and Writing Based on In-depth Learning in Senior High School - Take Unit 3 Computers as an Example
}

\author{
Jie Wang \\ China West Normal University, Nanchong 623300, Sichuan, China \\ DOI: $10.32629 /$ jher.v2i6.580
}

\begin{abstract}
In-depth learning is a learning method, which can transfer knowledge and solve problems in various complex and real situations through learners' critical understanding and thinking towards learning content. Guided by the subject core competence, the integrated course of English reading and writing should combine autonomous and cooperative learning to promote the perceptual understanding, and then design multi angle writing training such as text structure imitation, plot rewriting and ending continuation, so as to promote the application and transfer of language knowledge to promote students' in-depth learning.
\end{abstract}

Keywords: in-depth learning, integrated course of reading and writing, teaching design

\section{Introduction}

At present, the integrated course of English reading and writing only focuses on students' mastery of words and sentence patterns. And it also stays at the superficial level such as ask students to translate articles and imitate sentences. Compared with the current domestic research hotspot "in-depth learning", "deep education" or "deep teaching" should also keep pace with it and receive full attention. The concept of "in-depth education" and the method of "in-depth teaching" have not been put forward in China, but the practice has long been used in teaching. These kinds of tasks not only affects students' language skill learning and fails to meet the requirements of "cultivating people's lifelong learning ability", but also affects the development of students' in-depth learning ability, which is contrary to the purpose of "cultivating subject core competence".

\section{Concepts identification}

\subsection{In-depth learning}

Marton, F. \& Salj, R. first put forward the theory of in-depth learning. They believe that in-depth learning is the process of understanding, applying, analyzing and constructing knowledge. In this way, people can improve the overall knowledge and transform it into a knowledge system. With the development of relevant domestic research and the continuous promotion of the new curriculum reform, the cultivation of students' subject core competence and in-depth learning ability have been paid more and more attention. Therefore, this study believes that in-depth learning can lead learners to realize critical understanding, and then transfer knowledge to various real and complex situations to apply and solve problems.

\subsection{The integration of reading and writing}

Reading material is an important way for students to perceive and understand knowledge, and composition is an effective way to test reading results. Therefore, in the integrated course of reading and writing, teachers should arrange enough time to help students perceive the reading materials, deepen their understanding of the text, and learn the cohesive means and sentence structure. In writing activity, we should establish a consistent standard to evaluate and clarify the awareness of standardized writing, and then let students conduct self-evaluation and peer evaluation. Pay attention to the accumulation of beautiful words and sentences in the materials.

In the class teachers can integrate text structure analysis, key word and sentence analysis and writing thinking training. Therefore, Teachers should grasp the in-depth learning essentials of "writing through reading". Starting from reading text, excavate textual elements and provide students with diversified cognitive understanding methods, and then imitate the textual structure, rewrite the textual plot. In the multi angle writing training such as story ending, the comprehensive knowledge will promote the formation of students' high-order thinking and in-depth learning ability. 


\section{Case study}

With an aim to develop students' subject core competencies, the General Senior High School English Curriculum advocates adopting an activity-based approach to English learning and some other ways of learning such as autonomous learning, cooperative learning, and inquiry-based learning. Teachers should design integrated, relevant, and practical English learning activities so that students can participate in a variety of learning tasks such as learning and understanding, applying and practicing, and transfer and innovation, which integrate language, culture, and thinking. Therefore, guided by cultivating students' in-depth learning ability, this paper designs integrated course of reading and writing Unit 3 Computers to explore how to reflect progression of learning understanding, application practice, migration and innovation in classroom teaching.

\subsection{Pre-class preview}

Computers focuses on the training of listening, speaking, reading and writing skills around the theme of "computer technology". In the second part of this unit, Andy - the Android vividly introduces the components of Android system by using the story of robot playing football. In the previous learning, students have mastered passive voice and some expressions related to technology in life. This unit requires students to master the expression of common science and technology in real communication activities, and grasp the relationship between science and technology.

Considering that some students may have difficulties in understanding the text, teachers can prepare students in advance with the help of guiding questions such as "how many advantages do you know about Android? Please give examples".

\subsection{Understanding and application activity \\ 3.2.1 Brainstorming}

Teachers can prepare pictures related to science and technology in advance and throw out topics, such as "what can you see in the pictures" and "what do you know about Android", then filter the answers of students and start brainstorming, such as "What adjectives can be used to describe the advantages of the Internet?" After discussion in the group, students send representatives to report the group's views. Students' preview before class lays a foundation for teachers' classroom guidance and teaching

\subsubsection{Show pictures or questions}

After students have a preliminary understanding of the article in the brainstorming session, teachers can turn to indepth thinking training for students. Before reading the text, teachers can ask questions according to the topic, such as "make predictions of the context according to the title", "what do you think of Android/robots and why". If the students' answers involve key words and sentences that have not been learned, the teacher can show them without explaining them, which can not only cultivate the students' ability to infer word meaning in combination with the situation, but also remove some obstacles for follow-up teaching. Moreover, the students' logical thinking ability can also be trained in the process of language expression and relieve them from brainstorming activities.

\subsubsection{Reading and writing}

If reading an article is like visiting a building, the title is the first impression of the building. Extensive reading is to observe the macro framework, and intensive reading is to analyze the internal structure. When students have a preliminary impression in the previous activity, teachers can use "what's the main idea of the passage", "how many parts are included in this passage" and other questions let students quickly build the macro framework, find out the information such as theme, event and character relationship, and then combine "what's the relationship between the first three paragraphs" to understand supplement the internal structure.

\subsubsection{Rewriting the plot of the article}

Rewriting is an important way to reflect the connotation of promoting writing by reading. Taking Andy - the Android as an example, the full text tells the reasons why the network is important to Android from the first person perspective, so teachers can try to guide students to write to Android from the second person perspective based on the original text to explain why the network is important to it. It can also be combined with "Android ideas". These activities can help students understand the text theme from different angles, and generate the exchange and collision of views through continuous mental operation activities such as cognition, judgment and thinking in the process of rewriting.

\subsubsection{Imitation of article structure}

If you are a robot and meet a pair of kind-hearted but doting parents who often ask you to monitor their children's behavior, what do you think? What would you do if the child asked you to help with his homework? Would you refuse him? This task has no obvious connection with the content of the reading text, which is conducive to students' independent creation and cultivate innovative spirit, but it is also easy to ignore the application of new knowledge and cannot make students apply what they have learned. At this time, teachers can start with the text structure and guide students to conduct 
targeted learning and reasonable imitation with the situational writing task, such as learn "on the one hand... On the other hand..." Teachers should remind students to consciously choose their own words and sentences to strengthen their impression. In the process of repeated practice and imitation, students can deepen their understanding of reading the text; expand their thinking angle and writing ideas to promote their own in-depth learning.

\subsubsection{Innovation}

\subsubsection{Continuation the end of the article}

Andy - the Android introduces the components of the Android system and the functions of each system. At the end, it roughly explains the important role of computers in the Android system. Based on this, students may think about what these roles are and how to play them. These ideas are the key for students to continue writing. Therefore, on the basis of being loyal to the theme of the original text, teachers can guide students. This process is not only the process of students' innovative thinking, but also the process of promoting the improvement of in-depth learning ability.

\subsubsection{Comprehensive training of language skills}

Teachers can set some guidance problem to let students understand text content, such as "what can we infer from the last sentence" and other detailed inference questions, or "what's the meaning of 'stripper' in the fifth sentence". In addition, the exercises at the end of the text can also be used to create some interesting activities, such as an English corner to train oral English ability, "If you can design an Android, what kind of things would you like it to do? Give your reasons", "A teacher wants a robot to help him with his teaching in his class, do you agree with the idea? If so, how and why", etc. These activities can fully integrate the instrumental and humanistic characteristics of English, stimulate students' in-depth thinking.

\section{Conclusion}

No matter what teaching method is used, teachers should not only train students' test taking skills, but also adhere to the guidance of the core quality of the discipline. On the basis of consolidating students' language ability, they should pay attention to the development of their learning ability, thinking quality, cultural awareness and other qualities, and promote the cooperation between low-order thinking and high-order thinking, so as to cultivate students' ability with In-depth learning ability.

\section{References}

[1] Marton, F. \& Salj, R. (1976). On qualitative differences in learning — II outcome as a function of the learner's conception of the task. British Journal of Educational Psychology, 46(2): 115-127.

[2] The Ministry of education of the People's Republic of China. (2020). General Senior High School Curriculum Standards. Beijing: People's education press. 